\title{
Living and Working with HIV/AIDS: A Lifelong Process of Adaptation
}

\author{
André Samson and Habib Siam \\ University of Ottawa, \\ Faculty of Education
}

Canada

\section{Introduction}

Advancements in scientific knowledge and pharmacological therapies have led to the suppression of HIV replication in infected individuals and the concomitant recovery of immune function. This, in turn, has prompted a dramatic decline in the morbidity and mortality rates associated with HIV infection (UNAIDS, 2010; Werth, Borges, McNally, Maguire, \& Britton, 2008). As a consequence, the majority of people living with HIV (PWHIV) who have access to anti-retroviral therapy and to the appropriate medical followups experience a higher quality of life and longer life expectancy. A study conducted in Denmark estimated the median survival time for a young person diagnosed with HIV today at 38.9 years (Lohse et al., 2007).

A primary consequence of this evolution is that PWHIV must learn to adapt to their infection over the long term. The etymology of the verb " to adapt" stems from the Latin roots "ad", which means "towards", and "aptus", which signifies "apt," in the sense of something that is suitable. Therefore, "to adapt" literally means to move towards a suitable outcome or resolution. In the case of HIV/AIDS infection, successful adaptation involves restoring a sense of normalcy to one's everyday life, where "normalcy" is defined by PWHIV according to their perceived needs and situation. This process of adaptation involves numerous aspects, including medical/physical, psychological/affective, social, spiritual and vocational. Therefore, it is crucial to gain an in-depth understanding of how this process of adjustment unfolds.

In an effort to develop such an understanding, this chapter presents and describes a comprehensive theoretical model that accounts for the different aspects of this specific adaptive process. This chapter is divided into two main sections: the first is entitled "living with HIV/AIDS" and the second "working with HIV/AIDS". The former of the two sections is dedicated to developing a comprehensive task-based model of adaptation (CTBMA) to HIV/AIDS that incorporates the following five components: source of stress, cognitive appraisal, adaptive tasks, coping skills and outcome. The latter section describes a very specific adaptive task, the vocational one, that stems from the fact that HIV/AIDS is now categorized as a chronic illness that develops over the long term. Since it is now possible to lead an active life while living with HIV/AIDS, it is pertinent to understand how work helps PWHIV adapt to their infection. 


\section{Living with HIV}

A comprehensive understanding of the adaptation process may help guide diagnosed patients, family members and their relatives through the many uncertainties they face and help them find a way to stabilize the sudden disruption they have experienced. Furthermore, health care professionals may be better equipped to understand their patients' efforts to adapt. A comprehensive look at adaptation processes could also provide policy makers with a broader view of the psychosocial ramifications and implications of living with HIV/AIDS in the age of anti-retroviral therapies.

Numerous theoretical models describe the adaptation to major life transitions, in general, and to the onset of chronic illness, in particular (Samson \& Siam, 2008; Samson, Siam \& Lavigne, 2007). The literature also shows that the slew of approaches can be grouped into two main paradigms, the first of which proposes that individuals adapt by moving through a set of phases. An example of this theoretical paradigm is Kubler-Ross' (1969) stage-based model, which has had a particularly important impact on health care professional working with palliative patients. Staged-based approaches have been subject to numerous critiques, primarily because their rigid linearity is seen as imposing on patients a prescriptive way to adapt to their condition or situation. This normative aspect does not take into consideration the highly subjective manner in which individuals learn to adapt to a HIV diagnosis. Ascribing to stage-based approaches may therefore lead to the exclusion of those patients who do not follow these predetermined stages, as well as to the imposition of unfounded expectations on medical personnel (Corr, 1992).

The second paradigm revolves around the notion that adaptation to change is achieved by accomplishing a non-linear series of adaptation tasks (Samson 2006; Corr et al, 2003; Corr, 1992; Cohen \& Lazarus, 1979; Moos \& Tsu, 1977). This approach to adaptation appears to present a more effective alternative to the process of psychosocial adaptation to chronic illness and, more specifically, to HIV/AIDS. This theoretical model sets forth the notion that the adaptation process is based on the completion of certain tasks. Corr (1992) defines tasks as "work that may be undertaken by those who are coping"(p.83) and deems such efforts essential to resolving life challenges. In other words, tasks can be understood as efforts undertaken to reconstruct one, or many, specific aspects of life that has been affected by the contraction of HIV/ AIDS (Samson, 2006).

\section{Task-based model of adaptation to HIV/AIDS}

\subsection{Core assumptions of the comprehensive task-based model of adaptation (CTBMA)}

This comprehensive task-based model of adaptation (CTBMA) to chronic illness, and to HIV/AIDS in particular, is based on five core assumptions, as well as five components that will be described in the coming sections. The first core assumption is based on the fundamental premise that the process of adaptation to chronic illness is highly individual. As Corr (1992) states, health care professionals should avoid normative models like stagebased approaches, because these models exclude patients that do not comply with a prescribed set of phases. In this sense, the task-based model does not delineate an ideal way to adapt - the ideal manner being the one that the patient chooses to follow.

Secondly, the CTBMA is essentially phenomenological and transactional in nature. Indeed, through primary and secondary cognitive appraisal, patients continually evaluate and reevaluate the impact of HIV/AIDS on different aspects of their everyday lives (Cohen \& Lazarus, 1979). This is why patients diagnosed with chronic illness do not perceive their 
condition in a uniform way. The importance given to cognitive appraisal underlies the highly individual nature of this adaptive process. Thirdly, the integrated model is based on the assumption that individuals possess an innate drive to achieve, and subsequently maintain, social and psychological homeostasis with the objective of regaining a sense of normalcy and satisfaction in life (Moos \& Tsu, 1977).

The fourth assumption of the CTBMA is that the process of adaptation usually revolves around the reconstruction of aspects of the patients' lives that have been affected by the onset of chronic illness. Through this process of reconstruction, patients attempt to regain a sense of control over their lives. The fifth and final assumption of the CTBMA is that this process moves towards achieving either a positive or a negative outcome. Patients reach a positive outcome when they successfully reconstruct and reintegrate the aspects of their lives that have been affected by the onset of chronic illness. In other words, patients develop a sense of normality that does not deny or ignore the actual or potential physical or psychological consequences of their illness. Negative outcomes occur when patients are unable to cognitively appraise their diagnosis as a challenge that can be overcome. This perception is rooted in patients' belief that they do not possess the personal, social and professional resources to adapt. Negative outcomes can manifest themselves in the form of psychological deterioration, unsatisfactory social relationships, and difficulty to comply with medical treatment.

\subsection{Components of the comprehensive task-based model of adaptation (CTBMA)}

The framework that underpins the comprehensive task-based model of adaptation hinges on five components. The first component consists of the patient's history and social context; the second of cognitive evaluations of the diagnosis. The third consists of the different adaptation tasks; the fourth of the different coping skills and the fifth of the final outcome (Figure 1).

\section{Component 1: Patient's personal history and social context}

The CTBMA accounts for individuals' particular situation, or overall context, when news of the diagnosis is received. The context entails patients' life history, which encompasses ethnic origins, socio-economic status, previous life transitions and the quality of social support networks. It is crucial to account for these different personal aspects, as they have the potential to impact how patients perceive what is occurring to them. In this regard, patients' background and personal history may potentially impact the process of adaptation, both positively and negatively. According to Moos and Tsu (1977), it is the interplay of these factors that may influence the process of adaptation, to some degree at least.

\section{Component 2: Cognitive appraisal of the diagnosis}

The initial impact of the diagnosis and the subsequent achievement of adaptation tasks hinges on the individual cognitive appraisal of the stressor - which is the diagnosis itself. As mentioned in the description of the first component, this cognitive appraisal is contingent on patients' personal history and social context. The cognitive evaluation of the diagnosis is a primary determinant of the process of adaptation to chronic illness, in general, and to HIV/AIDS, in particular (Cohen \& Lazarus, 1979). Therefore, the diagnosis does not affect individuals in a uniform manner because the experience itself is a function of individual perception or cognitive appraisal. 


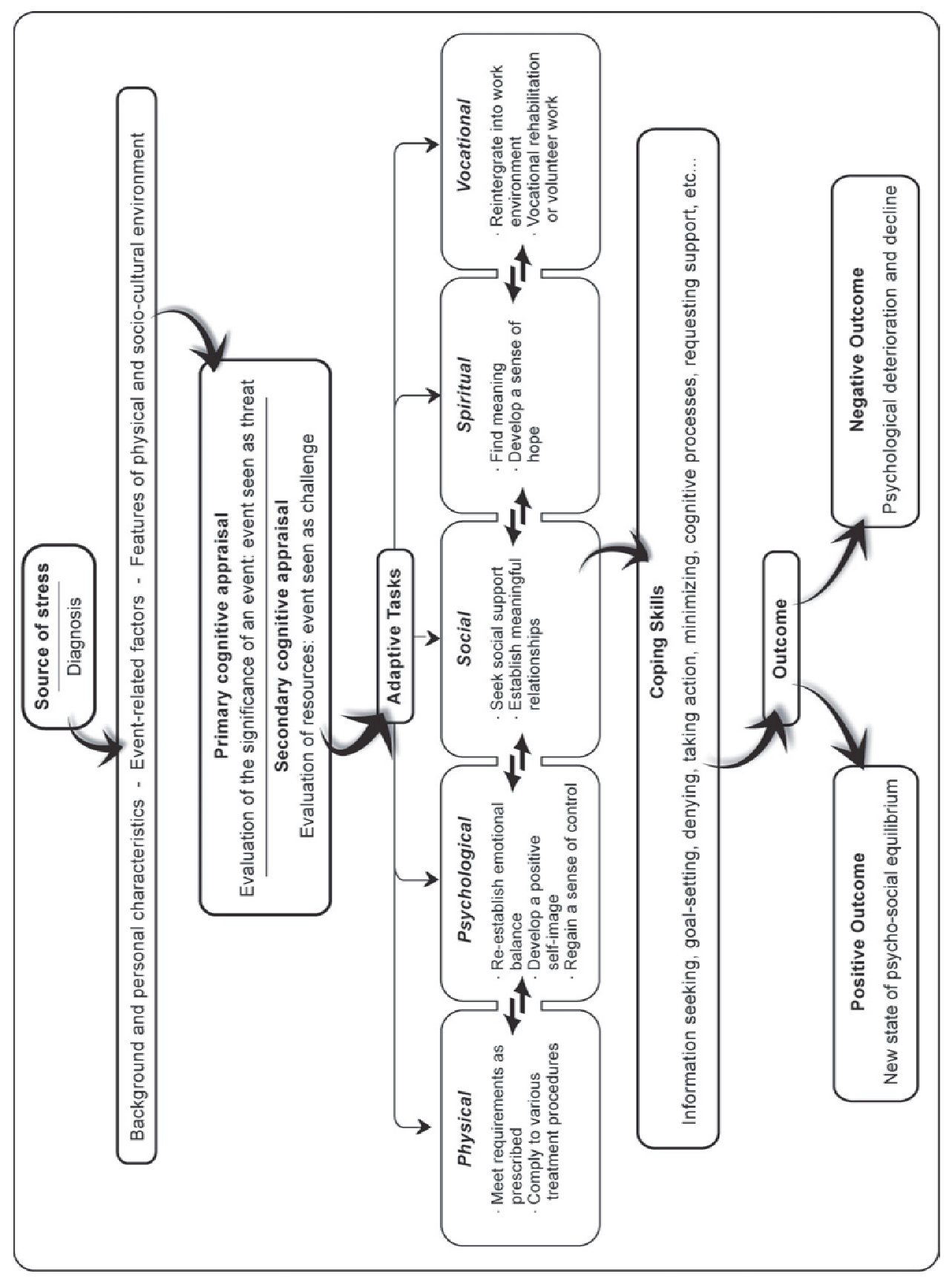

Fig. 1. Comprehensive task-based model of psychosocial adaptation to HIV/AIDS. 
Cognitive appraisal can be classified into two categories: (a) primary appraisal and (b) secondary appraisal. Primary appraisal is the initial perception of the impact of the diagnosis, which may be perceived as being threatening, benign-positive, or irrelevant (Cohen \& Lazarus, 1979). Primary appraisal is associated with the breaking news of a diagnosis. Perceiving the diagnosis as threatening triggers different psychological responses, such as denial, fear, anxiety, resentment or even anger. These reactions are usually indicators that patients believe that the diagnosis has taxed their resources to the extent that their reality is perceived as being hopeless.

With time, these reactions tend to diminish. The diagnosis gradually becomes a part of patients' lived, daily reality and the perceived threat of diagnosis diminishes. This evolution usually engenders a secondary appraisal, which indicates that patients have begun to perceive their illness as a challenge that requires adaptive efforts. More specifically, secondary appraisal consists of evaluating personal resources and alternatives in order to deal with the challenges, restrictions and demands that the illness imposes. It is the secondary appraisal that mobilizes patient efforts necessary to initiate the adaptation to the new medical condition. This shift in patients' cognitive appraisal of the illness and its impact helps them reconstruct a new sense of normalcy. Furthermore, cognitive appraisal is not a static process; rather, it is fluid and transactional because it evolves depending on patients' personal situation.

Component 3: Adaptive tasks.

Adaptive tasks form the third (and core) component of the CTBMA. These tasks encompass the principal aspects of human functioning that allow the process of adaptation to occur. The adaptive tasks are of a physical, psychological, social, spiritual and vocational nature.

The physical task consists primarily of meeting all medical requirements as prescribed by health care professionals. These may include the intake of medication, compliance to various treatment procedures and a healthier lifestyle that includes regular exercise and a balanced diet. The psychological task involves maintaining satisfactory emotional equilibrium and regaining a sense of control over one's life. The social task aims at gaining effective social support from significant others, friends and family. The spiritual task of adaptation is an effort at giving meaning to the onset of the illness and all the consequences it engenders.

Given the advancements in medical knowledge and interventions, patients living with chronic illness tend to enjoy longer life expectancies and a better overall quality of life. As a result, they are increasingly capable of maintaining an active lifestyle and engaging in meaningful activities. As such, it is important to incorporate a vocational task into the adaptation model. Through this task, which includes work that is both paid and unpaid, patients may resume their professional occupations, give a new orientation to their career or get involved in volunteer work. By accomplishing the vocational task, patients may find meaning in life, forge social status and establish a personal identity (Riverin-Simard, 2002). The accomplishment of these five adaptive tasks can be achieved simultaneously or in succession, with the accomplishment of a specific task potentially facilitating that of another. This process may vary from one individual to the next, depending on their appraisal of the illness, their personal situation and overall coping skills.

Component 4: Coping skills.

The fourth component of the CTBMA consists of coping skills. If adaptation tasks are seen as the general domains of adjustment, then copings kills may be understood as the specific 
means used to accomplish these tasks (Moos \& Tsu, 1977). Furthermore, these skills, which embody both a mental and behavioral aspect, are likely to be used in conjunction with one another, rather than individually.

Coping skills include, but are not limited to, denying or minimizing the seriousness of diagnoses, seeking relevant information, requesting reassurance and emotional support, learning specific illness-related procedures, setting concrete limited goals, rehearsing alternative outcomes and finding a general purpose or pattern of meaning in the course of events. According to Cohen and Lazarus (1979) coping is defined as any effort aimed at managing, tolerating, and

minimizing the difficulties, restrictions, and demands typically associated with stressful life events. In summary, a coping skill is a cognitive or behavioral ability used to accomplish a specific task. These skills can be pre-existing at the moment of the diagnosis, or learned during the process of adaptation to the illness.

Component 5: Outcome.

Finally, the concluding component of the CTBMA is that of outcome. According to Moos and Tsu (1977) and Cohen and Lazarus (1979), there are two possible outcomes: (a) positive and (b) negative. While the former is indicative of a new state of psychosocial equilibrium, highlighted by a reestablished sense of normalcy, the latter alludes to a certain degree of psychological deterioration and decline. In other words, a positive outcome is achieved when the illness is seen as less of a disruption and becomes an accepted aspect, among others, of patients' lives. Patients regain a certain sense of control over the course their existence and develop a new perception of life satisfaction (Samson, 2006).

In summary, the CTBMA is predicated on how patients cognitively appraise the impact of illness on their lives. This appraisal is mediated by patients' personal history and context. When patients perceive their illness as a challenge that can be overcome, they begin the process of adaptation. This process is determined by the tasks patients need to accomplish in order to reestablish a sense of normalcy in their lives. These tasks are of a physical, psychological, social, spiritual and vocational nature. The accomplishment of these tasks mobilizes patients' existing coping skills and catalyzes their abilities to learn new ones. At the end of the adaptation process, patients resume a train of life that may be different from the one they led before the diagnosis but is nonetheless a source of satisfaction. Illness is perceived as less of a threatening stranger and more of an unwanted companion: life is different but normal again.

Extensive research has been conducted on the conceptualization and understanding of the first four adaptation tasks. However, little is the vocational aspect of the process of adaptation. This is why the remainder of the chapter focuses on this specific aspect of the CTBMA.

\section{Working with HIV/AIDS}

\subsection{Introduction}

This second section describes the content and analyzes the aspects of the vocational task, based on empirical research that has been conducted on the role of paid and unpaid work in the process of adaptation to HIV/AIDS. The rationale behind this section is that the current body of research concerns itself primarily with the physical, psychological, social and spiritual adaptive tasks related to HIV/ AIDS. Researchers have paid insufficient attention to 
the vocational task (Samson, Lavigne \& MacPherson, 2009). The dearth in scientific studies is partially explained by the fact that, until the recent past, PWHIV were unable to resume their professional activities or to maintain an active life. With advancements in pharmacological interventions, this is no longer the case. Most PWHIV are now able to lead productive lives, despite their infection, which is why it is important to pay special attention to the vocational task and its contribution to the process of adaptation.

Work is probably one of the most normative activities in individuals' lives. It brings financial autonomy, helps create social networks, allows for self-expression, and provides the possibility to contribute to the common good. In fact, in a globalized economy, work is probably the main aspect of individual identity and a primary contributor to finding meaning in life (Samson, 2006; Riverin-Simard, 2002). This is why one of the principal negative impacts of being diagnosed with a major chronic illness is the deprivation of the ability to work. This, in turn, may lead to social marginalization, a loss of personal identity, and the perception that tangible social contributions are no longer achievable. In this context, the resumption of work activities can therefore be interpreted as an important step in the achievement of a positive outcome in the adaptation process (Samson \& Siam, 2008; Samson, 2006).

\subsection{The vocational task in the context of adaptation to HIV/AIDS}

When it comes to PWHIV, many factors can motivate a return to the job market. A qualitative study identified some of these motivations and showed that working helped the 30 participants feel useful and fulfilled (Brooks \& Klosinski, 1999). Work also restores meaning to people's existence, gives them the opportunity to contribute to society, to expand their social network, and to regain a sense of normality. In addition, remunerated work leads to a certain amount of financial independence and can alleviate the social shame and stigma associated with being on social assistance (Conyers, 2004).

In a study conducted by Blalock, McDaniel and Farber (2002), participants living with HIV/AIDS who were also employed reported enjoying a significantly higher quality of life than did their unemployed counterparts. This finding supports the evidence-based notion that work is a contributing factor to recovery and healing (Escovitz \& Donegan, 2005). People who successfully return to work after a period of disability have better health indices and shorter durations of disability than people who do not return to work (Martin, Steckart, \& Arns, 2006).

Research has shown that there are undeniable benefits to professional reintegration for PWHIV, which positively contributes to the adaptation to HIV/AIDS. The accomplishment of the vocational task can even aid in the completion of other tasks, most notably through the expansion of meaningful social networks, a rise in self-esteem and self-efficacy, and the development of a renewed sense of meaning in life.

Nevertheless, the accomplishment of the vocational task may be complicated by a number of barriers and challenges. Job market re-entry is indeed a complex process and, in certain circumstances, may require professional assistance (Escovitz \& Donegan, 2005). According to some researchers, living with HIV/AIDS constitutes a handicap and returning to work may require a form of assistance similar to that which is generally provided to individuals with a physical disability (Arns, Martin, \& Chernoof, 2004). The types of obstacles faced by PWHIV can be medical, professional, social, or financial in nature (Goldblum \& Kohlenberg, 2005; Martin, Brooks, Ortiz, \& Venigas, 2003; Martin et al., 2006; Werth et al., 2008). Over 
91\% of PWHIV that participated in a 2006 study conducted by Martin et al. (2006) reported experiencing at least one of the above listed barriers during their efforts to return to work. First, medical barriers are directly related to the consequences of the infection. It remains difficult to predict the rate at which immunodeficiency will develop due to HIV infection and exactly when antiretroviral therapy will be required (Argentier, Fernet, Levy, Bastien, \& Fernet, 2003). This uncertainty in prognosis and difficulties in anticipating medical intervention can weigh heavily on PWHIV and their future expectations. Though most PWHIV now enjoy a higher quality of life, many issues, such as resistance to drugs, still cause high levels of uncertainty. This element of the unknown hinders and complicates vocational development and professional reintegration (Brooks \& Klosinski, 1999; Hoffman, 1997; Martin et al., 2003).

One of the more significant side effects associated with HIV/AIDS treatment is lipodystrophy or body fat redistribution. Individuals with lipodystrophy lose fat from their face, arms, legs, and buttocks and gain fat in the abdomen and upper back. For some, this fat redistribution can be significant and disfiguring. This may not only affect self-esteem, but can also significantly impact those whose occupation involves interaction with the public (Argentier et al., 2003). In addition, there is fear that stress related to work could be detrimental to overall health or that the workplace could constitute an environment where there is a risk of contracting an infection (Arns et al., 2004).

A realistic return to the job market must take into consideration individuals' health status. The professional activities must be adjusted to the limits and boundaries associated with the illness (Hunt, Jaques, Niles, \& Wierzalis, 2003). For the poor or near poor, issues of finding and maintaining a job often take precedence over larger decision-making processes, such as choosing among a variety of job opportunities (Werth et al., 2008).

The second type of barrier is associated with career issues and vocational development. The competitiveness of the job market, fueled by a globalized economy, affects all people, regardless of whether or not they are living with HIV/AIDS. PWHIV, however, face additional challenges that limits their vocational flexibility. For example, PWHIV may require ongoing medical care and monitoring, which are usually provided by specialists and are generally only accessible in large urban centers. Such geographic restrictions on job mobility can affect employability and opportunities for advancement (Timmons \& Fesko, 2004).

As supported by existing research, it is obvious that today's economic dynamics can complicate PWHIV's reentry into the job market. Not only do they have to cope with the current economic climate, as do all employees, but they also have to take into account the limitations their medical situation imposes. Furthermore, PWHIV may be forced to find new types of occupations, as their professional activities may have become too physically demanding and their medical status may no longer tolerate the kind of stress generated by their work. Furthermore, this imposed career transition may be difficult to achieve as it may require a certain amount of retraining and the acquisition of new professional skills in a field of activity that is less labor-intensive (Maguire, McNally, Britton, Werth, \& Borges; 2008).

The third type of barrier is caused by the social stigma afflicting PWHIV (Herek, Capitanio, \& Widaman, 2002). This stigma has the potential to obstruct PWHIV's efforts for job market reentry. In fact, the majority of PWHIV experience some form of rejection or discrimination in the workplace (Brooks et al., 2004). Specifically, they worry that the accidental disclosure of their condition may lead to a form of exclusion, slow the progression of their career, or even lead to job termination (Brooks \& Klosinski, 1999; Hoffman, 1997). A recent study 
confirms that PWHIV not only experience stigma, but also different forms of abuse (Maguire et al., 2008).

Social stigma related to HIV/AIDS manifests itself in a multiplicity of ways. For example, PWHIV may worry about having to explain or justify their medication intake or the recurring physician consultations scheduled during work hours (Hunt et al., 2003). PWHIV may also worry about the possible humiliation they may be subject to because of the bureaucratic procedures necessary to obtain benefits (Conyers, 2004).

The fourth type of barrier is financial in nature. In certain jurisdictions, returning to work may lead to the termination of long-term disability benefits, a drawback that is compounded by PWHIV's inability to regain these benefits in the event that their health begins to deteriorate. Preoccupation with this potential loss of financial security can lead to increased stress and worry, to the point of debilitating PWHIV in their vocational decision-making (Brooks et al., 2004; Ferrier \& Lavis, 2003). Brooks et al. (2004) concluded that, of a sample of 536 unemployed PWHIV, 73\% of those contemplating a return to work ranked the fear of losing their disability income as the most significant barrier to the resumption of professional activities.

In conclusion, many obstacles confront PWHIV who wish to return to work and further their careers. Even though a number of PWHIV perceives a return to work as a plausible possibility, reentering the job market can be daunting for some and can therefore jeopardize the process of adaptation.

Under these circumstances, volunteer work may constitute a more realistic option. Research has shown that volunteer work in other medical and social contexts can be a form of personal investment and achievement (Conyers, 2004). Samson et al. (2009) conducted a study on PWHIV engaged in volunteer work and the role of these activities in facilitating the adaptation process. Their qualitative analysis showed that volunteer work could be an alternate way to regain an active lifestyle. More specifically, this research found that volunteer work allows participants to enrich their social lives, to regain a sense of psychological wellbeing, and to apply their abilities to the benefit of others.

One of the more interesting conclusions of this qualitative research is that participants justify their choice to volunteer for HIV/AIDS organizations by explaining that they wish to avoid discrimination and social stigma. In other words, when it comes to volunteer work, PWHIV choose to contribute to organizations that deal with their condition. In doing so, they avoid any form of stress associated with social stigma. The participants are driven by a protective instinct that makes them want to be on familiar ground and to be in an environment where HIV/AIDS is not stigmatized.

In comparison to paid work, where secrecy seems to mitigate the social stigma associated with HIV/AIDS, the choice of the right organization appears to be the solution to prevent social alienation when it comes to volunteering engagements. Both of these strategies involve protective measures, the first of which leads to a form of clandestine behavior where PWHIV are forced to hide their condition from their coworkers, while the second limits PWHIV's choices of volunteer organizations. Despite these restrictions, volunteer work provides a certain degree of flexibility and freedom not normally associated with remunerated work.

In summary, the vocational task appears to be an important aspect of the CTBMA, specifically in contexts where there is an increase in the number of PWHIV who are able to maintain an active lifestyle. Empirical data shows that the accomplishment of this specific task enhances the satisfaction and overall quality of life of PWHIV. Nevertheless, there exist 
a number of barriers that impede professional reintegration and must be overcome for PWHIV to accomplish a successful reentry into the job market. Finally, it seems that volunteer work can be a viable alternative to remunerated employment.

\section{Conclusion}

Given the advancements in scientific knowledge and the progress in medicine, major chronic illnesses have, and will continue to, become manageable conditions that are no longer considered as debilitating as they once were (Samson \& Siam, 2008). Consequently, individuals diagnosed with chronic diseases are increasingly capable of maintaining active lifestyles. This is particularly true for PWHIV. As previously discussed, it is important for people living with chronic illness, in general, and with HIV/AIDS, in particular, to adapt to their condition over the long term. A comprehensive model that theorizes the different aspects of the adaptation process is crucial in enhancing our understanding of how individuals with chronic illness adapt to their new medical reality and strive to reestablish a certain sense of normalcy in their lives.

The CTBMA proposes an exhaustive description of how people adapt to the onset of a chronic illness. The model includes five components and five adaptive tasks, which are medical, social, psychological, spiritual and vocational. The primary strength of this model is that it accounts for the highly individual nature of the adaptation process. Rather than prescribe an ideal way to adapt, the model posits that adaptation should be dictated by the individual context and reality. However, it appears that the vocational task is becoming an increasingly important aspect of the adaptation process. This may be caused by the fact that work is one of the most normative aspects of individuals' lives and that people with chronic illness are more capable of rejoining the workforce than they once were. These trends should invite a renewed focus on the vocational task and the role of work, paid or unpaid, in the adaptation process.

\section{References}

Argentier, S., Fernet, M., Levy, J. J., Bastien, R., \& Fernet, R. (2003). Les médicaments antirétroviraux et al VIH/sida: Entre espoir et scepticisme. Frontières, 16(1), 4456.

Arns, P. G., Martin, D. J., \& Chernoff, R. A. (2004). Psychosocial needs of HIV-positive individuals seeking workforce re-entry. AIDS Care, 16(3), 377-386.

Blalock, A. C., McDaniel, J. S., \& Farber, E. W. (2002). Effect of employment on quality of life and psychological functioning in patients with HIV/AIDS. Psychosomatics, 43(5), 400-404.

Brooks, R. S., Martin, D. J., Ortiz, D. J., \& Venigas, R. C. (2004). Perceived barriers to employment among persons living with HIV/AIDS. AIDS Care, 16, 756-766.

Brooks, R. A., \& Klosinski, L. E. (1999). Assisting persons living with HIV/AIDS to return to work: Programmatic steps for AIDS service organizations. AIDS Education and Prevention, 11(3), 212-223.

Cohen, F., \& Lazarus R. S. (1979). Coping with the stress of illness. In: C. G. Stone, F. Cohen, N., \& E. Adler (Eds), Health psychology: A handbook (pp. 217-254). San Francisco, CA: Jossey-Bass. 
Conyers, L. M. (2004). Expanding understanding of HIV/AIDS and employment: Perspectives of focus groups. Rehabilitation Counseling Bulletin, 48(1), 5-18.

Corr, C. A., Nabe, C. M., Corr, D. M. (2003). Death and dying, life and living. Belmont, CA: Wadsworth.

Corr, C. (1992). A task-based approach to coping with dying. Omega, 24, 81-94.

Escovitz, K., \& Donegan, K. (2005). Proving effective employment supports for persons living with HIV: The KEEP project. Journal of Vocational Rehabilitation, 22, 105-114.

Ferrier, S.E., \& Lavis, J.N. (2003). With health comes work? People living with HIV/AIDS consider returning to work. AIDS Care, 15(3), 423-435.

Goldblum, P., \& Kohlenberg, B. (2005). Vocational counseling for people with HIV: The client-focused considering work model. Journal of Vocational Rehabilitation, 69, 3036.

Herek, G. M., Capitanio, J. P., \& Widaman, K. F. (2002). HIV-related stigma and knowledge in the United States: Prevalence and trends, 1991-1999. American Journal of Public Health, 92(2), 371-377.

Hoffman, M. A. (1997). HIV disease and work: Effect on the individual, workplace, and interpersonal contexts. Journal of Vocational Behavior, 51, 163-201.

Hunt, B., Jaques, J., Niles, S. G., \& Wierzalis, E. (2003). Career concerns for people living with HIV/AIDS. Journal of Counseling and Development, 81(1), 55-67.

Kubler-Ross, E. (1969). On death and dying. New York, NY: McMillan Publishing Company.

Lohse, N., Hansen, A. B., Pedersen, G., Kronborg, G., Gerstoft, J., Sørensen, H. T., et al. (2007). Survival of persons with and without HIV infection in Denmark. Annals of Internal Medicine, 146(2), 87-95.

Maguire, C. P., McNally, C. J., Britton, P. J., Werth, J. L., \& Borges, N. J. (2008). Challenges of work: Voices of persons with HIV disease. The Counselling Psychologist, 36(1), 42-89.

Martin, D. J., Steckart, M. J., \& Arns, P. G. (2006). Returning to work with HIV/AIDS: A qualitative study. Work, 27, 209-219.

Martin, D. J., Brooks, R. A., Ortiz, D.J., \& Venigas, R. C. (2003). Perceived employment barriers and their relation to workforce entry intent among people with HIV/AIDS. Journal of Occupational Health Psychology, 8, 181-194.

Moos, R. H, \& Tsu, D.V. (1977). Coping with physical illness. NewYork, NY: Plenum Medical Company.

Riverand-Simard, D. (2002). Le sens du travail et la carrièrologie. Carrièrologie, 8, 303-320.

Samson, A., Lavigne, R., \& MacPherson, P. A. (2009). Self-fulfillment despite barriers: Volunteer work of people living with HIV. AIDS Care, 21(11), 1425-1431.

Samson, A., \& Siam, H. (2008). Adapting to major chronic illnesses: A proposal for a comprehensive task-model approach. Patient Education and Counseling, 70(3), 426429.

Samson, A., Siam, H. \& Lavigne, R. (2007). Psychosocial adaptation to chronic illness: description and illustration of an integrated task-based model. Interventions, 127, $16-28$.

Samson. A. (2006). L'apport de la carrière au modèle théorique des taches d'adaptation a la maladie chronique: une application au cas des personnes qui vivent avec le VIH. Canadian Journal of Counselling, 40, 4-16. 
Timmons, J. C., \& Fesko, S. L. (2004). The impact, meaning, and challenges of work: Perspectives of individuals with HIV/AIDS. Health $\mathcal{E}$ Social Work, 29(2), 137144.

United Nations Programs on HIV/AIDS. (2010). Global report: UNAIDS report on the global AIDS epidemic 2010. Geneva, Switzerland: WHO Library.

Werth, J. L., Borges, N. J., McNally, C. J., Maguire, C. P., \& Britton, P. J. (2008). The intersections of work, health, diversity, and social justice: Helping people living with HIV disease. The Counselling Psychologist, 36(1), 16-41. 


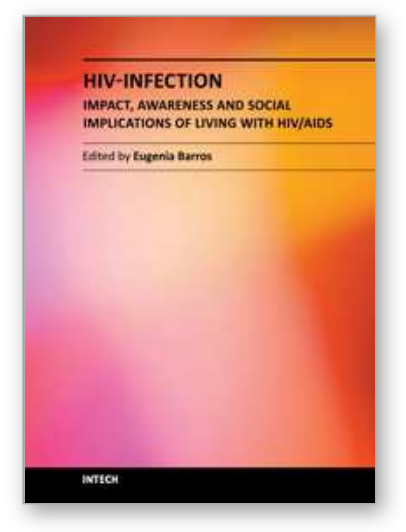

\author{
HIV-infection - Impact, Awareness and Social Implications of living \\ with HIV/AIDS \\ Edited by Dr. Eugenia Barros
}

ISBN 978-953-307-343-9

Hard cover, 336 pages

Publisher InTech

Published online 26, October, 2011

Published in print edition October, 2011

The past few decades have seen the escalation of HIV-infections and the 'frantic' search for new drugs to treat the millions of people that live with HIV-AIDS. However because HIV-AIDS cannot be cured, but only controlled with drugs, and the Antiretroviral (ARV) treatment itself results in some undesirable conditions, it is important to generate wider awareness of the plight of people living with this condition. This book attempts to provide information of the initiatives that have been used, successfully or unsuccessfully, to both prevent and combat this 'pandemic' taking into consideration the social, economic, cultural and educational aspects that involve individuals, communities and the countries affected.

\title{
How to reference
}

In order to correctly reference this scholarly work, feel free to copy and paste the following:

André Samson and Habib Siam (2011). Living and Working with HIV/AIDS: A Lifelong Process of Adaptation, HIV-infection - Impact, Awareness and Social Implications of living with HIV/AIDS, Dr. Eugenia Barros (Ed.), ISBN: 978-953-307-343-9, InTech, Available from: http://www.intechopen.com/books/hiv-infection-impactawareness-and-social-implications-of-living-with-hiv-aids/living-and-working-with-hiv-aids-a-lifelong-process-ofadaptation

\section{INTECH}

open science | open minds

\section{InTech Europe}

University Campus STeP Ri

Slavka Krautzeka 83/A

51000 Rijeka, Croatia

Phone: +385 (51) 770447

Fax: +385 (51) 686166

www.intechopen.com

\section{InTech China}

Unit 405, Office Block, Hotel Equatorial Shanghai

No.65, Yan An Road (West), Shanghai, 200040, China

中国上海市延安西路65号上海国际贵都大饭店办公楼405单元

Phone: +86-21-62489820

Fax: +86-21-62489821 
(C) 2011 The Author(s). Licensee IntechOpen. This is an open access article distributed under the terms of the Creative Commons Attribution 3.0 License, which permits unrestricted use, distribution, and reproduction in any medium, provided the original work is properly cited. 